\title{
A Educação Em Tempos De Pandemia: Primeiras Aproximações Teórico-Reflexivas
}

\section{Emanuel Mangueira Carvalho'}

\section{RESUMO}

Este trabalho tem o objetivo de apresentar e problematizar a realidade educacional das escolas e dos alunos no tocante as necessidades estruturais e materiais, que são essenciais para garantir a oferta da Educação de qualidade na modalidade remota de ensino, que é o recurso utilizado nesse momento de pandemia do coronavírus para a oferta da educação. Para isso, o artigo iniciou o assunto apresentando a definição e as características das Tecnologias da Informação e Comunicação (TIC). Em seguida, o artigo abordou a definição de Educação, os avanços da Educação na última década do século $X X$ e nas duas primeiras décadas do Século XXI, momento em que também ocorreu um retrocesso nos investimento da Educação com a aprovação de Proposta de Emenda Constitucional. Por último, foram apresentadas e problematizadas as informações que mostram a realidade da educação pública, no tocante as condições de acesso a recursos tecnológicos da TIC e do acesso a internet, uma vez que esses são requisitos essenciais para garantir, na modalidade remota de ensino utilizada na pandemia, a educação de qualidade para os alunos.

Palavras-chave: Educação. Política Educacional. Tecnologia da Informação e Comunicação.

\section{ABSTRACT}

This work aims to present and problematize the educational of school and of student's reality in terms of structural and material needs, who is essential to guarantee the quality in the offer of teaching in the mode of e-learning education, which is the resource used at this time during the coronavirus pandemic for the provision of education. To this end, the article started the subject by presenting the definition and characteristics of Information and Communication Technologies (ICT). Then, the article addressed the definition of education, the advances in education in the last decade of the twentieth century and the first two decades of the twenty-first century, when there was also a setback in investment in education with the spending ceiling by the Constitutional Emendation Proposal. Finally, information showing the reality of

\footnotetext{
1 Doutorado e mestrado em Educação pela Faculdade de Educação da Unicamp (Universidade Estadual de Campinas) com bolsa de estudos da CAPES/DS. Graduado em Pedagogia pela Faculdade de Educação da Unicamp. Graduado em Letras Licenciatura plena pela AESOC (Associação de Ensino Superior de Osvaldo Cruz. Atualmente, é professor efetivo da Educação Básica da Prefeitura de Hortolândia/SP atuando no Ensino Fundamental. ORCID: https://orcid.org/0000-0002-8637-5430
} 
public education was presented and questioned, regarding the conditions of access to technological resources of ICT and access to the internet, since these are essential requirements to guarantee, in the remote modality of teaching used in the pandemic, quality education for students.

Keywords: Education. Policy Education. Information and Communication Technologies

\section{Introdução}

Atualmente, a educação básica vem enfrentando um novo desafio que é o uso dos recursos tecnológicos para garantir o acesso à educação de seus alunos. As inserções das Tecnologias da Informação e Comunicação (TIC) já ocorrem na educação há alguns anos e "na sociedade contemporânea, o uso das TIC está inserido no dia a dia através dos diversos equipamentos eletrônicos e digitais que permitem o acesso convergente de mídias". (ANGELUCI; CACAVALLO, 2017, p. 64).

Com o advento da pandemia, em decorrência do coronavírus "Sars-Cov-2" (UNASUS, 2020), as TIC tem se apresentado como sendo praticamente a alternativa mais viável, apesar de não ser a única, para garantir o ensino e ao mesmo tempo respeitar as orientações da Organização Mundial da Saúde (OMS) para evitar o contágio e a disseminação do "vírus" (ORGANIZACIÓN MUNDIAL DE LA SALUD, 2020). A pandemia impôs o uso da TIC na educação, o que exigiu praticamente da noite para o dia, adaptações rápidas para a nova realidade educacional.

No entanto, o uso das TIC, além de recursos tecnológicos, exigem estruturas mínimas para se efetivar. Com isso, ofertar o ensino na modalidade remota ou on-line, recursos estes que têm sido utilizadas durante a pandemia para garantir a oferta da educação escolar, exigem acessos a insumos e também a internet. Aqui é importante destacar que

A mediação pelas tecnologias não ocorre somente em cursos EAD (Educação a Distância) totalmente on-line, mas também está presente dentro das escolas tradicionais de diversas formas, desde o uso de laboratórios de informática para suporte do aprendizado, passando pelo uso do computador dentro da sala de aula para apoio do professor, até a aplicação de uma ou algumas disciplinas de forma totalmente virtual. (ANGELUCl; CACAVALLO, 2017, p. 64).

Para continuar a discussão é pertinente situar que a definição de educação básica utilizada neste artigo fundamenta-se na Lei de Diretrizes e Bases da Educação Nacional, conhecida como LDB. Isso porque, a LDB em seu artigo 21, inciso I, define que a educação básica é "formada pela educação infantil, ensino fundamental e ensino médio" (BRASIL, 1996b).

Já a concepção de Educação deste artigo tem como base Saviani (2016) no qual se entende a educação como sendo inerente da sociedade humana "originando-se do mesmo processo que deu origem ao homem. Desde que o homem é homem ele vive em sociedade e se desenvolve pela mediação da educação." (SAVIANI, 2016, p.1). 
É evidente, segundo o eminente pesquisador, que a educação e sua finalidade passam por intensas mudanças com a evolução da sociedade. Apesar de toda abordagem histórica feita por Saviani (2016), sobre a importância da educação para a sociedade na qual o autor infere que, a medida que a sociedade evoluiu, os interesses que a educação representava em cada período dessa evolução também foram se alterando, para este artigo, destaca-se a educação da sociedade moderna que é a que mais se adequa a este trabalho. Nas palavras do eminente pesquisador,

\begin{abstract}
Nesse contexto, a forma principal e dominante de educação passa a ser a educação escolarizada. Diante dela a educação difusa e assistemática, embora não deixando de existir, perde relevância e passa a ser aferida pela determinação da forma escolarizada. A educação escolar representa, pois, em relação à educação extraescolar, a forma mais desenvolvida, mais avançada. E como é a partir do mais desenvolvido que se pode compreender o menos desenvolvido e não o contrário, é a partir da escola que é possível compreender a educação em geral e não o contrário. Parafraseando Marx, se não é possível compreender a renda imobiliária sem o capital, mas é possível compreender o capital sem a renda imobiliária, dir-se-ia que, na sociedade moderna, não é possível compreender a educação sem a escola, mas é possível compreender a escola sem a educação. É, assim, no âmbito da sociedade moderna que a educação se converte de forma generalizada, numa questão de interesse público a ser, portanto, implementada pelos órgãos públicos, isto é, pelo Estado o qual é instado a provê-la através da abertura e manutenção de escolas. (SAVIANI, 2016, p.3-4).
\end{abstract}

Por conseguinte, torna-se mais viável avançar na discussão do assunto da educação em tempos de pandemia. E, para isso, será abordado um pouco mais sobre a educação.

\title{
1. A Educação e a Política
}

Como já é sabido, o direito a educação é garantido a todos na Constituição da República Federativa do Brasil, promulgada em 5 de outubro de 1988, especificamente em seu artigo $6^{\circ}$, o que também caracteriza a educação como sendo um direito social.

Contudo, é apenas na seção I, do capítulo III, do título IV da Carta Magna que é possível observar os elementos essenciais para o desenvolvimento da educação, por exemplo, como se dará o dever do Estado para com a educação, bem como a distribuição do repasse das receitas oriundas de impostos, além de outros determinantes necessários para garantir a todos a educação de qualidade. (BRASIL, 1988).

No entanto, ao se comentar sobre o dever do Estado com a educação não se pode deixar de mencionar os interesses e também a influência de organizações internacionais sobre a oferta da educação no Brasil. Essa influência tem acontecido por longas décadas do século XX no Brasil e exercem grande influência ainda nos dias atuais.

Existem problemas ainda mais complexos, que dizem respeito às relações entre o Brasil e outras sociedades capitalistas como, por exemplo, a dominação imperialista da Europa avançada, dos Estados Unidos e do Japão, sobre o Brasil. Ou ainda o fato 
de nós termos tido uma comissão MEC-USAID, que acabou calibrando toda a reordenação jurídica de nosso sistema educacional. É notória a introdução de concepções que degradam e subestimam o ensino público, enaltecendo o ensino privado e que acabam por fortalecer a ideia de que a educação, para ser responsável, precisa ser sobretudo uma mercadoria. (FERNANDES, 1989, p.169-170. Grifos do autor).

A influência de agências internacionais na educação brasileira é possível ser observada por toda da década de 1990 do século XX, desde o governo Collor seguido pelo governo de Fernando Henrique Cardoso (FHC).

O governo Fernando Henrique vem dando continuidade às reformas liberalizantes, ampliando o processo de abertura econômica, intensificando o processo de privatizações e aprovando uma série de mudanças constitucionais que abrem caminho para o aprofundamento das reformas. (SOARES, 2000, p.36).

Nesse sentido, é possível inferir que muitas medidas políticas implementadas na educação, na década de 1990, entre elas as políticas educacionais coincidiram com as proposta do Banco Mundial.

Muitas mudanças em curso coincidem com as propostas do Banco, como a reforma do sistema previdenciário, a revisão do sistema tributário, a flexibilização dos monopólios, a concentração dos recursos para educação no ensino básico, entre outras. (SOARES, 2000, p.37. Grifos meus).

Por conseguinte, compreende-se o porquê da lei n. 9.424 de 24 de dezembro de 1996, lei que regulamentou o FUNDEF (Fundo de Manutenção e Desenvolvimento do Ensino Fundamental e de Valorização do Magistério) tiveram os seus recursos direcionados exclusivamente para o ensino fundamental.

Já no decorrer dos anos 2000 foi possível observar o esforço por parte do governo Lula em ampliar os recursos para toda a educação básica e não somente para o ensino fundamental. Isso aconteceu com a aprovação da lei n. 11.494 de 20 de junho de 2007, ou seja, a lei que criou o FUNDEB (Fundo de Manutenção e Desenvolvimento da Educação Básica e de Valorização dos Profissionais da Educação). Com o FUNDEB o repasse de verbas passou a contemplar todas as etapas escolares que pertence à educação básica atendendo desde a educação infantil até o ensino médio.

Para completar a linha de raciocínio, destaca-se como exemplo o investimento no ensino superior, com a aprovação da Lei n. 11.892 de 29 de dezembro de 2008, que criou os Institutos Federais de Ciência e Tecnologia. Assim, nota-se que na primeira década do século XXI além da ampliação do investimento para toda a educação básica o Governo Lula investiu no ensino superior o que não aconteceu no governo anterior conforme destacado em Soares (2000).

A segunda década do século XXI, ou seja, a partir do ano de 2010, teve início com a 
eleição da primeira mulher Presidente da República, Dilma Rousseff (G1, 2010). Além disso, Dilma Rousseff conseguiu outro feito histórico que foi ser a primeira Presidente da República reeleita na história do País (O GLOBO, 2014).

Porém, o que parecia ser uma promissora continuidade de um governo que muito investiu nas causas sociais, principalmente na educação, não aconteceu. No ano de 2016 a Presidente Dilma teve o mandato cassado através do processo de "impeachment" (SENADO NOTÍCIAS, 2016). E, ainda no mesmo ano, foi aprovada a Proposta de Emenda a Constituição n.55 - (PEC-55) conhecida como PEC do teto que impôs um teto de gasto para as contas públicas por um período de 20 anos. (SINIMBÚ; JADE, 2016).

Por conseguinte, é aqui o momento oportuno para construir a articulação entre a educação e a sua forma de oferta nesse momento de pandemia, pois, foi logo após esse período de declínio de investimento na educação que surgiu a pandemia em decorrência do coronavírus.

No início do ano de 2020, especificamente em janeiro, a OMS foi informada sobre o vírus Sars-Cov-2 que naquele momento ainda não tinha nome definido. (PAIVA, 2020). Contudo, somente no início de março de 2020 que o novo "coronavírus" foi definido como pandemia. E ainda naquele mês, no caso do Brasil, muitos governadores e prefeitos decidiram fechar as escolas públicas e privadas com a finalidade de conter a disseminação do novo coronavírus. (UNASUS, 2020).

Contudo, o fechamento das escolas não permaneceu por muito tempo, e em setembro de 2020 foi autorizada a abertura das escolas para atividades de reforço escolar e, posteriormente, para as aulas presenciais no mês de outubro daquele mesmo ano (G1, 2020). Cabe esclarecer que o Estado de São Paulo exigiu que para o retorno das aulas presenciais seria necessário que o Estado estivesse na fase amarela durante todo o mês de setembro.

Além disso, o retorno à escola, dos alunos, deveria acontecer de forma gradual e no modelo de revezamento. As escolas seriam adaptadas para cumprir os protocolos de segurança para garantir o retorno seguro as aulas, o que iria garantir o acesso à escola, o respeito ao distanciamento social e a oferta das aulas presenciais.

\section{A Tecnologia da Informação e Comunicação na Educação}

Para continuar a discussão, cabe destacar que, ao mesmo tempo em que se discutia como deveria ocorrer o retorno as aulas presenciais, também era discutido como continuar o processo de ensino dos alunos enquanto as escolas estivessem fechadas ou se o retorno às aulas presenciais ocorresse no formato de revezamento.

É sabido que a opção para continuar com a oferta de ensino foi utilizar a modalidade remota com o uso, por exemplo, das aulas on-line. Comentou-se até mesmo sobre o ensino híbrido, porém essa modalidade é a mais difícil de ser utilizada nesse momento de pandemia. 
Isso porque, conforme pode ser constatado na entrevista concedida pelo professor Fernando Trevisani $^{2}$ para a revista nova escola ficou claro que

o ensino híbrido é composto por modelos de atividades que integram momentos presenciais e on-line, no qual recursos digitais são utilizados para coletar dados e informações que visam a personalização do ensino. E aqui vale destacar um equívoco comum: não é possível pensar em uma implementação do modelo em uma realidade em que os alunos não estão $100 \%$ de forma presencial. "Não tem como implementar ensino híbrido em aula remota, é possível se inspirar nos modelos de ensino híbrido de modo a utilizar ideias deles no ensino remoto, mas implementar nessas realidades conforme foram originalmente pensados, não", determina o educador. (SALAS, 2021, p. $n / c)$.

Assim, apesar de não ser possível implementar o ensino híbrido nesse momento de pandemia, dado as suas peculiaridades, está claro que a modalidade remota de ensino ou, as aulas on-line, beneficiam-se dos recursos tecnológicos, por exemplo, utilização de WhatsApp, blog e de outros recursos para o desenvolvimento do ensino e aprendizado dos alunos.

Ainda nesse ínterim, cabe destacar que outro assunto que ganhou destaque foi a preocupação com a formação docente, no sentido de os professores estarem preparados para utilizarem os recursos tecnológicos para o ensino remoto ou aulas on-line. É evidente que a formação docente é importante e não se pode negar essa peculiaridade que é inerente da atividade educacional do professor, afinal,

Ensinar é uma atividade específica da prática social humana, que acaba por exigir algumas pré-condições pessoais e também determina uma atuação e desenvolvimento pessoal a partir de muita dedicação, atualização, estudo, pesquisa e trabalho. É assim que analisamos e projetamos as possíveis disposições para uma política emancipatória de formação de educadores, de formação permanente de professores. (NUNES; ROMÃO, 2013, p.165).

Desse modo, enfatiza-se que a formação docente é importante e que ela certamente deve acontecer, porém, cabe destacar que já se completou um ano de pandemia onde, de forma on-line ou remota, muitos professores têm assegurado o aprendizado dos alunos, o que mostra o empenho, a capacidade de aprendizado dos professores que se adaptaram as formas on-line e remota de ensino, uma vez que a oferta da educação não deixou de acontecer desde o início da pandemia.

De modo geral, está claro que a pandemia exigiu uma rápida adaptação dos profissionais envolvidos com a educação e pode-se citar, como exemplo, a articulação dos professo-

\footnotetext{
${ }^{2}$ Fernando de Mello Trevisani. Licenciado em Matemática pela Universidade de São Paulo (USP) 2009. Mestre em Educação Matemática pela Universidade Estadual Paulista Júlio de Mesquita Filho (UNESP) 2013. Fonte: http://lattes.cnpq.br/6697400693760168 Acesso em: 17. Mar. 2021.
} 
res com a equipe gestora das escolas. Isso porque, a oferta da educação e do planejamento do ensino não poderia parar, ainda que as escolas ficassem fechadas. Com isso, atividades como o Horário de Trabalho Pedagógico Coordenado (HTPC), Conselho de Classe e Reunião de Pais, acabaram ocorrendo de forma remota e com o uso de aplicativos, por exemplo, do "zoom" e do "google met".

Entretanto, é importante situar que a educação nesse momento de pandemia, além das adaptações que acometeram os profissionais da educação, conforme foi destacado acima, exige mudanças que insiram nas escolas infraestrutura e recursos tecnológicos para ofertar a educação.

Recursos estes que, por consequência da pandemia, devem ser estendidos para a família dos alunos. "Afinal, de nada adianta estar atualizado com as principais tendências tecnológicas do ensino, preparar o corpo docente para essas mudanças e não oferecer uma estrutura propícia para a inovação" (MINHA BIBLIOTECA, 2018, p. n/c).

Além disso, a função do professor mais uma vez passou por transformação. Isso porque "o professor, diante das variadas funções que a escola pública assume, tem de responder a exigências que estão além de sua formação". (OLIVEIRA, 2004, p. 1132). Ainda segundo o autor, "o trabalho docente amplia o seu âmbito de compreensão e, consequentemente, as análises a seu respeito tendem a se complexificar". (OLIVEIRA, 2004, p.1132).

Cabe enfatizar também que apesar de todas as dificuldades que se fazem presente para os educadores, a Pandemia deixou latente para toda a sociedade a precariedade da educação pública, o que para muitos certamente não é novidade.

A pandemia acentuou a necessidade de recursos tecnológicos que são essenciais para garantir o desenvolvimento da Educação. Entre esses recursos podemos destacar a necessidade de acesso a internet na sala de aula para os professores e acesso a internet nas escolas para os alunos, além de acesso a computadores. E, conforme será abordada na sequência, essa estrutura também se faz necessária para a família dos alunos.

Entretanto, é sabido que a maioria das escolas padece com a falta de insumos, por exemplo, computadores nas salas de aulas, falta de acesso a internet e, aliado a isso, não se pode esquecer que na maioria das vezes a escola está em local sem acesso a esses recursos tecnológicos.

Um estudo organizado pelo lede (Interdisciplinaridade e Evidências no Debate Educacional), com base em dados do Programa Internacional de Avaliação de Alunos (Pisa) de 2015, mostra que o Brasil tem a segunda pior conectividade nas escolas entre os países que participaram do levantamento. Segundo a análise, $28,3 \%$ dos estudantes do Brasil afirmaram que têm acesso a computadores com internet nas escolas. A porcentagem perde apenas para a República Dominicana, com 28,18\%. A média de conexão dos países da Organização para a Cooperação e Desenvolvimento Econômico (OCDE), é de 55,9\%. (CRAIDE, 2018, p. n/c). 


\section{A Educação na Pandemia: Problematizações Sobre a Realidade Educacional}

Com a pandemia muitos professores tiveram que utilizar de recursos próprios para desenvolver a sua atividade profissional. Ou seja, passou a utilizar a internet de sua própria casa, utilizar o seu próprio computador e até mesmo o próprio celular, para as situações de contatos realizados via WhatsApp. Observa-se assim que os insumos que os professores adquiriram para planejar e organizar a atividade docente, na pandemia passou a ser ferramenta essencial de trabalho, e certamente esses recursos foram obtidos pelos próprios professores. Além disso, não é demais relembrar que os recursos tecnológicos tornam-se rapidamente obsoletos, o que exige investimento constante dos recursos tecnológicos.

Outro elo na relação da educação em tempos de pandemia são as condições das famílias dos alunos que frequentam a escola. Afinal, refletir sobre a educação nesse contexto exige considerar a realidade familiar e os recursos necessários para participar das aulas na modalidade remota ou on-line.

A mesma infraestrutura que é necessária que a escola tenha para desenvolver uma educação de qualidade em tempos de pandemia, ou para fazer o uso das TIC nas escolas, é uma estrutura que também é necessária que a família dos alunos tenha a sua disposição. Isto é, acesso a internet, a computadores e tablet.

É sabido que muitas famílias vivem em localidades sem acesso a internet e na maioria das vezes o acesso a internet é feito pela internet disponibilizada pelo celular. "Quase 40\% dos alunos de escolas públicas não tem computador ou tablet em casa” (OLIVEIRA, 2020, p. $\mathrm{n} / \mathrm{c}$.) Ainda segundo a autora,

Os dados mostram o cenário em que a educação entrou na pandemia em 2020 e indicam possível desafio no ensino remoto, montado às pressas quando houve necessidade de fechamento das escolas para evitar a propagação do coronavírus. Sem computadores e conexão à internet, é possível que os estudantes tenham dificuldade para acessar os conteúdos online, que têm substituído as aulas presenciais. (OLIVEIRA, 2020, p. n/c).

E a situação pode ser até pior, pois há famílias que tem acesso a um único aparelho de celular que, na maioria das vezes, é compartilhado por todos, inclusive para o desenvolvimento das atividades escolares de seus filhos. E algumas vezes esse aparelho é utilizado pelos pais durante o dia devido a necessidade de trabalhar, o que acaba fazendo com que o aluno apenas tenha acesso ao celular após o retorno dos pais para casa o que geralmente ocorre no período da noite, tornando este o único momento viável para o alunos realizar as atividades escolares.

No Brasil, cerca de seis milhões de estudantes, desde a pré-escola até a pós-graduação, não têm acesso à internet banda larga ou 3G/4G em casa e, consequentemente, não conseguem participar do ensino remoto. Desses, 5,8 milhões são alunos de instituições públicas de ensino. É o que diz o estudo "Acesso Domiciliar à Internet 
e Ensino Remoto Durante a Pandemia", feito pelo Instituto de Pesquisa Econômica Aplicada (Ipea). Os alunos do ensino fundamental são os mais afetados. Juntos, os anos iniciais e os anos finais somam mais 4,35 milhões de estudantes sem acesso, sendo 4,23 milhões de escolas públicas. No ensino médio, estima-se que, de 780 mil adolescentes que não dispõem de internet em casa, 740 mil são da rede pública. Já a pré-escola pode ter até 800 mil crianças sem conexão, sendo que 720 mil frequentam o ensino público (ARAÚJO, 2020, p. n/c).

Desse modo, é necessário construir e disponibilizar formas de acesso aos recursos tecnológicos para as famílias poderem atender as demandas educacionais de seus filhos. A disponibilidade dessa estrutura, na casa dos alunos, tornará viável o aproveitamento do processo de aprendizagem, uma vez que permitirá que o aluno e a família estruturem suas dinâmicas e rotinas de estudos contribuindo para o processo de desenvolvimento do aluno, enquanto perdurar o ensino na modalidade remota em decorrência da pandemia.

Dos 5,8 milhões de estudantes de escolas públicas que não têm conexão, apenas 2,6 milhões dispunham de sinal de rede móvel celular. O estudo afirma que, destes, aproximadamente 800 mil precisam somente de um chip de dados, porque já dispõem de computador, tablet, celular ou notebook. No entanto, quase 1,8 milhões de alunos da rede pública não têm esses equipamentos e precisam contar com a distribuição de celular ou tablet para se conectar. Ainda assim, aproximadamente 3,2 milhões continuariam sem acesso, pois não têm sinal de rede móvel onde moram. (ARAÚJO, 2020, p. n/c).

Nesse sentido, é importante problematizar de forma urgente as condições reais que os alunos têm em casa para participar do desenvolvimento do ensino remoto ou das aulas on-line, isso porque, já está claro que estar atento a essa necessidade é extremamente importante. Afinal, retomar as aulas presenciais nesse momento é extremamente arriscado, coloca em risco a vida dos professores, dos funcionários, dos alunos e dos familiares de todos que estão envolvidos com as escolas. (FERRARI; FIUZA, 2021.)

Conforme apresentado neste artigo, existem alternativas viáveis para o ensino nesse momento de pandemia que é o uso da tecnologia. Os recursos tecnológicos além de resguardar a vida dos profissionais envolvidos com a Educação, garante o aprendizado necessário. Com infraestrutura e investimento adequado os recursos tecnológicos permitem a oferta da educação de qualidade, afinal, não se pode esquecer que estes recursos, mesmo de forma precária, ou seja, não atendendo a todos, já estão sendo utilizados.

Assim, os investimentos da área educacional devem ser direcionados para a possibilidade do uso das TIC na educação. As TIC permite assegurar o direito à Educação, com oferta de ensino remoto e aulas on-line, pois, todo conteúdo e processo de aprendizado podem ocorrer na modalidade remota de ensino, impedindo também a propagação do coronavírus.

Nesse sentido, o que se chama atenção é que existem alternativas viáveis, para cumprir com o direito a Educação. Afinal, a intenção não é omitir ou negar o direito a educação, 
mas sim apontar que existem alternativas que atendem aos interesses de todos. $\mathrm{O}$ uso dos recursos públicos para investimento na Educação, devem pautar essa possibilidade, o que certamente é benéfico para toda a população.

Por último, não se pode esquecer que os investimentos em recursos tecnológicos são caros, pois se tornam obsoletos de forma rápida, e precisam ser atualizados constantemente. Isso porque, entre os principais desafios para usar a TIC na educação são necessários "acompanhar o avanço do setor, manter os alunos engajados, oferecer infraestrutura adequada, escolher ferramentas tecnológicas estratégicas e inovar no ato de lecionar" (MINHA BIBLIOTECA, 2018, p. n/c).

Isso certamente exigirá mais atenção por parte das políticas públicas e o maior empenho para o investimento nas tecnologias. Porém é o melhor investimento que a Educação pode receber nesse momento, afinal, esses recursos estarão sempre disponíveis na escola para os alunos, tornando possível, em um futuro próximo, a inserção do ensino híbrido na educação.

\section{Considerações Finais}

A pandemia deixou evidente a falta de recursos para a execução do trabalho do professor na educação, o que talvez não seja novidade para os profissionais que trabalham na área. Contudo, a situação se agravou com a pandemia, pois a oferta do ensino passou a exigir o uso de recursos tecnológicos, por exemplo, o uso de internet, computadores, entre outros para assegurar o ensino remoto ou on-line. E, conforme foi apresentado, a maioria das escolas não têm esses recursos disponíveis e, para piorar a situação, muitas famílias também não possuem o suporte necessário para serem atendidas pelo ensino remoto.

A realidade, ainda em pleno século XXI, é que muitas escolas não dispõem de insumos, ou seja, laboratórios de informática e acesso de computadores para os professores, além de não ter acesso a internet. Nesse sentido, não é demais enfatizar que essa mesma estrutura tem que estar disponível nas casas dos alunos que precisa de acesso aos mesmos insumos para garantir a participação efetiva no ensino remoto ou on-line.

Já no que diz respeito a formação docente, é certo que a formação adequada para atuar com as TIC na educação é importante. Contudo, não se pode deixar de ressaltar que os professores tem se empenhado para garantir o aprendizado dos alunos, seja com o uso da modalidade remota de ensino, seja com aulas on-line, até mesmo porque a oferta do ensino não foi suspensa, com o advento da pandemia. O que mostra por parte dos professores o compromisso, o respeito e o empenho na aprendizagem dos alunos, o que consequentemente exigiu a adaptação e a aquisição do conhecimento das TIC por parte dos professores.

Nessa ordem de considerações, essas devem ser as primeiras atitudes a serem tomadas para garantir um bom resultado com a continuidade do uso do ensino remoto, ou de um possível retorno as aulas com a modalidade de ensino híbrido, afinal, a falta de insumos e de infraestrutura tanto para a escola, quanto para os alunos, serão prejudiciais para o desenvol- 
vimento da educação.

Até mesmo porque, caso não seja assim, será preciso esperar o acesso da população a vacina, para garantir um retorno seguro as aulas, o que certamente trará mais prejuízo para o processo educacional e de desenvolvimento dos alunos, haja vista que o acesso e a oferta da educação não podem deixar de ser oferecido, enquanto se espera que todos os profissionais da educação e até mesmo os alunos estejam vacinados.

\section{Referências}

ANGELUCI, Alan Cesar Belo; CACAVALLO, Marcello. Inovações no ensino híbrido: uma perspectiva a partir da teoria ator-rede. Comunicação \& Educação, [S. I.], v. 22, n. 1, p. 63-73, 2017. DOI: 10.11606/ issn: 2316-9125, v22i1, p. 63-73. Disponível em: https://dialnet.unirioja.es/servlet/articulo?codigo=6072196 acesso em: 26 mar. 2021.

ARAÚJO, Ana Lídia. Cerca de seis milhões de alunos brasileiros não tem acesso a internet. Segundo levantamento do Instituto de Pesquisa Econômica Aplicada (Ipea), aproximadamente 5,8 milhões são estudantes de instituições públicas. Correio braziliense - Eu estudante, educação básica. 4 set. 2020. Disponível em: https://www.correiobraziliense.com.br/euestudante/ educacao-basica/2020/09/4873174-cerca-de-seis-milhoes-de-alunos-brasileiros-nao-tem-acesso-a-internet.html acesso em: 17 mar. 2021.

BLANCHE, Robert. A epistemologia. Lisboa; Rio de Janeiro, RJ: Presença: Martins Fontes, 1975. 161p.

BRASIL. Palácio do Planalto. Constituição da República Federativa do Brasil de 5 de outubro de 1988. Texto consolidado até a Emenda Constitucional n. 107 de 2020. Brasília, DF: 1988. Disponível em: http://www.planalto.gov.br/ccivil_03/constituicao/constituicao.htm acesso em: 15 mar. 2021.

BRASIL. Palácio do Planalto. Lei n. 9.424 de 24 de dezembro de 1996. Dispõe sobre o Fundo de Manutenção e Desenvolvimento do Ensino Fundamental e de Valorização do Magistério. Brasília, DF: 1996a. Disponível em: http://www.planalto.gov.br/ccivil_03/leis/l9424.htm\#: :text=LEI\%20N\%C2\%BA\%209.424\%2C\%20DE\%2024\%20DE\%20DEZEMBRO\%20DE\%20 1996.\&text=Disp\%C3\%B5e\%20sobre\%20o\%20Fundo\%20de,Transit\%C3\%B3rias\%2C\%20 e\%20d\%C3\%A1\%20outras\%20provid\%C3\%AAncias acesso em: 16 mar. 2021.

BRASIL. Palácio do Planalto. Lei n. 9.394 de 20 de dezembro de 1996. Estabelece as Diretrizes e Bases da Educação Nacional. Brasília, DF: 1996b. Disponível em: http://www.planalto. gov.br/ccivil_03/leis/l9394.htm acesso em: 15 mar. 2021.

BRASIL. Palácio do Planalto. Lei n. 11.494 de 20 de junho de 2007. Regulamenta o Fundo de Manutenção e Desenvolvimento da Educação Básica e de Valorização dos Profissionais da 
Educação - FUNDEB. Brasília, DF: 2007. Disponível em: http://www.planalto.gov.br/ccivil_03/_ ato2007-2010/2007/lei/l11494.htm acesso em: 16 mar. 2021

BRASIL. Palácio do Planalto. Lei n. 11.892 de 29 de dezembro de 2008. Institui a Rede Federal de Educação Profissional, Científica e Tecnológica, cria os Institutos Federais de Educação, Ciência e Tecnologia, e dá outras providências. Brasília, DF: 2008. Disponível em: http://www. planalto.gov.br/ccivil_03/_Ato2007-2010/2008/Lei/L11892.htm acesso em: 16 mar. 2021.

CRAIDE, Sabrina. Estudo mostra que Brasil tem pouca conectividade na escola. Agência Brasil. 02 fev. 2018. Disponível em: https://agenciabrasil.ebc.com.br/educacao/noticia/2018-01/ estudo-mostra-que-brasil-tem-pouca-conectividade-nas-escolas acesso em: 19 mar. 2021.

FERNANDES, Florestan. O desafio educacional. São Paulo, SP: Cortez; Autores Associados, 1989. 264p.

FERRARI, Murillo; FIUZA, Renan. SP fecha 7 escolas por casos confirmados e suspeitas de Covid-19. CNN Brasil, São Paulo. 08 fev. 2021. Disponível em: https://www.cnnbrasil.com. br/nacional/2021/02/08/sp-fecha-7-escolas-por-casos-e-suspeitas-de-covid-19 acesso em: 20 mar. 2021.

G1. Dilma Rousseff é a primeira mulher eleita presidente do Brasil. Globo.com, Eleições 2010. 01 nov. 2010. Disponível em: http://g1.globo.com/especiais/eleicoes-2010/noticia/2010/10/dilma-rousseff-e-primeira-mulher-eleita-presidente-do-brasil.html acesso em: 16 mar. 2021.

G1. Governo de SP autoriza reabertura de escolas para atividades de reforço a partir desta terça-feira. Dos 645 municípios paulista, apenas 128 devem reabrir escolas. Capital e 38 cidades da região metropolitana resolveram adiar volta das atividades. Retomada das aulas presenciais está prevista para 7 de outubro no estado. G1 - São Paulo. 08 set. 2020. Disponível em: https://g1.globo.com/sp/sao-paulo/noticia/2020/09/08/governo-de-sp-autoriza-reabertura-de-escolas-para-atividades-de-reforco-a-partir-desta-terca-feira.ghtml acesso em: 16 mar. 2021.

MINHA BIBLIOTECA. TICs na educação: desafios das tecnologias de informação e comunicação. Minha Biblioteca, 2018. Disponível em: https://minhabiblioteca.com.br/tics-na-educacao/ acesso em: 18 mar. 2021.

NUNES, Cesar; ROMÃO, Eliana Sampaio. A educação brasileira, as novas diretrizes curriculares e a formação de professores. In: ROMÃO, Eliana Sampaio; NUNES, Cesar; CARVALHO, José Ricardo. Educação, Docência e Memória: desa(fios) para a formação de professores. Campinas, SP: Librum Editora, 2013. 175p.

OLIVEIRA, Dalila Andrade. A reestruturação do trabalho docente: precarização e flexibilização. Educ. Soc., Campinas , v. 25, n. 89, p. 1127-1144, Dec. 2004. Disponível em: http:// 
www.scielo.br/scielo.php?script=sci_arttext\&pid=S0101=73302004000400003-\&lng=en\&nrmiso Acesso em: 25 Mar. 2021. http://dx.doi.org/10.1590/S0101-73302004000400003.

OLIVEIRA, Elida. Quase $40 \%$ dos alunos de escolas públicas não têm computador ou tablet em casa, aponta estudo. Globo.com - Educação, 2020. Disponível em: https://g1.globo.com/ educacao/noticia/2020/06/09/quase-40percent-dos-alunos-de-escolas-publicas-nao-tem-computador-ou-tablet-em-casa-aponta-estudo.ghtml acesso em: 18 mar. 2021.

O GLOBO. Dilma Rousseff é reeleita presidente do Brasil. O Globo, Globo.com. 26 out. 2014. Disponível em: https://oglobo.globo.com/brasil/dilma-rousseff-reeleita-presidente-do-brasil-14368148 acesso em: 16 mar. 2021.

ORGANIZACIÓN MUNDIAL DE LA SALUD. Brote de enfermedad por coronavirus (COVID-19): orientaciones para el público. 7 out. 2020. Disponível em: https://www.who.int/es/emergencies/ diseases/novel-coronavirus-2019/advice-for-public acesso em: 15 mar. 2021.

PAIVA, Deslange. Da descoberta de uma nova doença até a pandemia: a evolução da Covid-19 registrada nos tuítes da OMS. Publicações da Organização Mundial da Saúde (OMS) apontam o avanço do número de casos da Covid-19 em três meses desde o surgimento do vírus. G1 - Bem-estar. 03 abr. 2020. Disponível em: https://g1.globo.com/bemestar/coronavirus/noticia/2020/04/03/da-descoberta-de-uma-nova-doenca-ate-a-pandemia-a-evolucao-da-covid-19-registrada-nos-tuites-da-oms.ghtml acesso em: 16 mar. 2021.

SALAS, Paula. Não tem como implementar ensino híbrido em aula remota. Fernando Trevisani, professor e especialista em metodologias ativas, fala tudo que você precisa saber e ninguém te conta sobre os modelos. REVISTA NOVA ESCOLA, 2021. Disponível em: https:// novaescola.org.br/conteudo/20152/nao-tem-como-implementar-ensino-hibrido-em-aula-remota\#_=_acesso em: 17 mar. 2021.

SANCHEZ GAMBOA, Sílvio Ancísar. Pesquisa em educação: métodos e epistemologias. Chapeco: Argos, 2007. 193 p.

SAVIANI, Dermeval. A lei da educação: trajetória, limites e perspectivas. $13^{a}$ ed. Revisada e ampliada. Campinas, SP; autores associados, 2016. 320p.

SENADO NOTÍCIAS. Impeachment de Dilma Rousseff marca ano de 2016 no Congresso e no Brasil. Senado Federal. 28 dez. 2016. Fonte: Agência Senado. Disponível em: https://www12. senado.leg.br/noticias/materias/2016/12/28/impeachment-de-dilma-rousseff-marca-ano-de-2016-no-congresso-e-no-brasil acesso em: 20 mar. 2021.

SINIMBÚ, Fabíola; JADE, Liria. Saiba o que muda com a aprovação final da PEC do Teto dos Gastos Públicos. AGÊNCIA BRASIL. Brasília, 13 dez. 2016. Disponível em: https://agenciabrasil.ebc.com.br/politica/noticia/2016-12/saiba-o-que-muda-com-aprovacao-final-da-pec-do-teto-dos-gastos-publicos acesso em: 16 mar. 2021. 
SOARES, Maria Clara Couto. Banco Mundial: políticas e reformas. In: TOMMASE, Lívia de; WARDE, Mirian Jorge; HADDAD, Sérgio. (ORG). O banco mundial e as políticas educacionais. $3^{a}$ ed. São Paulo, SP: Cortez, 2000. 279p

UNASUS. Organização Mundial de Saúde declara pandemia do novo Coronavírus:

Mudança de classificação obriga países a tomarem atitudes preventivas. Universidade Aberta do Sistema Único de Saúde. 11 mar. 2020. Disponível em: https://www.unasus.gov.br/noticia/organizacao-mundial-de-saude-declara-pandemia-de-coronavirus\#: :text=Organiza\%C3\%A7\%C3\%A30\%20Mundial\%20de\%20Sa\%C3\%BAde\%20declara\%20pandemia\%20 do\%20novo\%20Coronav\%C3\%ADrus,-Mudan\%C3\%A7a\%20de\%20classifica\%C3\%A7\%C3\%A3o\&text=Tedros\%20Adhanom\%2C\%20diretor\%20geral\%20da,Sars\%2DCov\%2D2 acesso em: 15. Mar. 2021 